\title{
Naturalization of Prunus pensylvanica L.f. (Rosaceae) in Novosibirsk
}

\author{
Anastasiya Belanova ${ }^{1, *}$, and Ludmila Chindyaeva ${ }^{1}$ \\ ${ }^{1}$ Central Siberian Botanical Garden, Siberian Branch RAS, 630090 Novosibirsk, Russia
}

\begin{abstract}
Naturalization of the North American species Prunus pensylvanica has been revealed in Novosibirsk for the first time. This species was introduced in the city in the middle of the last century. It naturally regenerates vegetatively in the area of landscape objects and in dedrological collections and gives self-seeding. In local conditions it is characterized by fast growth, short pregenerative period, presence of abundant uneven-aged progeny, high vegetative mobility, and local population-forming ability.
\end{abstract}

\section{Introduction}

Naturalization and distribution of alien plant species are one of the serious ecological problems in many regions of the world [1,2]. At present an active process of distribution of alien species is observed in Siberia [3]. Among naturalizing woody plants in Siberian cities there are representatives of North American flora, including Prunus L. species [4]. In Novosibirsk we noted an intensive natural regeneration of Prunus pensylvanica L.f. which was introduced in local conditions in the middle of the last century. $P$. pensylvanica regenerates vegetatively in large quantities at places of cultivation, penetrates in open forest stands, gives self-seeding, actively spreads in the area. Closely related North American Prunus serotina Ehrh. and Prunus virginiana L. have got an invasive status in European countries [5-7].

The aim of our study was assessment of the degree of P. pensylvanica naturalization in the second range in Novosibirsk.

\section{Materials and methods}

Study was conducted in green stands of Novosibirsk and dedrological collections in different districts of the city in 2009-2017. Seed and vegetative generations as individuals of seed origin, root suckers, and partial plants were noted. Trial fields for assessment of natural regeneration of $P$. pensylvanica were laid out. Age status of individuals was determined by T. A. Rabotnov (1987) [8]. The degree of naturalization was estimated with the use of appropriate classification [9].

\footnotetext{
* Corresponding author: boronina.a@inbox.ru
} 


\section{Results and discussion}

It was revealed that the alien species $P$. pensylvanica actively regenerated in the area of landscape objects and dendrological collections in Novosibirsk. It forms abundant unevenaged generation with predominance of fruit-bearing individuals, gradually expands the occupied territory and goes beyond habitats. High vegetative mobility and distribution of daughter plants at a considerable distance from maternal individuals, as well as self-seeding were recorded in $P$. pensylvanica. The species naturally forms large clump-clones on the illuminated sites, in places goes under the canopy of open stands, gives self-seeding on the forest margins. It was established that for the period of introduction in Novosibirsk P. pensylvanica sucessfully adapted in local conditions; it is winter-hardy and characterized by fast growth, stable in the urban environment growing in various ecological conditions - in parks, in the area of residentail development, near streets and roads.

In the arboretum of Siberian Research Institute of Plant growing and Breeding (SRIPGB) $P$. pensylvanica, planted in the amount of 23 specimens in 1989 г. (it was received by 3 -year old seedlings from Abakan and seeds from Central Siberian Botanical Garden (CSBG SB RAS), formed a local self-reproducing population. On the plot where 7 maternal trees 3,7 - 8,6 m high survived, natural regeneration of Prunus pensylvanica amounted to 63 specimens $\left(1-5\right.$ specimens per $\left.1 \mathrm{~m}^{2}\right)$. Flowering and fruit bearing are at the age of 4-5, ground seed germination in local conditions does not exceed $7 \%$. Among daughter individuals prevail generative: young (g1), middle-aged (g2) and old (g3) plants (Fig. 1). Regular single flowering and fruit bearing are noted in young generative individuals up to the age of 12 , abundant ones - in middle-aged (20 years old) individuals.

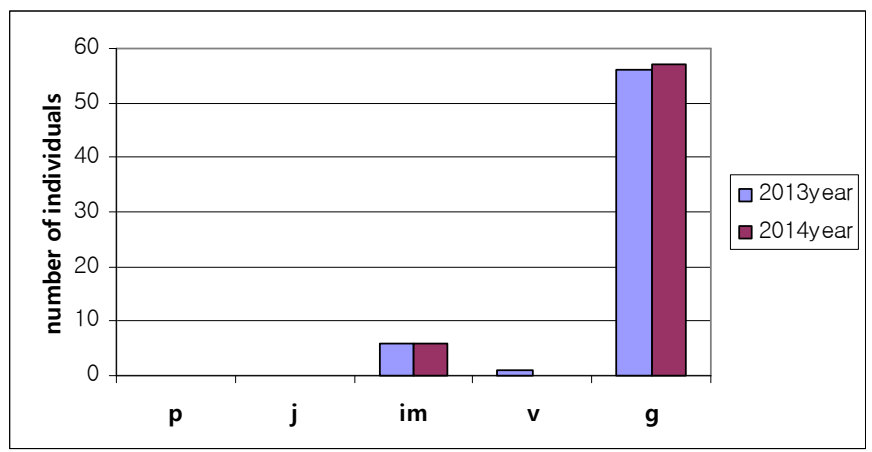

Fig. 1. The age spectrum of Prunus pensylvanica local population in the arboretum of SRIPGB: $\mathrm{p}$ - seedlings, $\mathrm{j}$ - juvenil age stage, im - immature, $\mathrm{v}$ - virginal, $\mathrm{g}$ - generative stage.

P. pensylvanica in Novosibirsk is not very long-lived, noticeable decrease in annual growth begins in middle-aged generative plants (Fig. 2). Old generative individuals represent the smalest group of fruit-producing plants (less than 5\% of population abundance), presence of up to $15-30 \%$ of drying out branches and xerocephalous features are characteristic of them. At the age of more than 30, dying off of the natural trunk is observed. Replacement of trunks by fast growing individuals of vegetative origin takes place in short time. In the community with domination of $P$. pensylvanica species diversity of herbaceous cover acounts for 26 species, the projective cover being from 47 to $96 \%$. In its second range in Novosibirsk the North American species $P$. pensylvanica is characterized by the same biological features which are peculiar to the plants in the natural range. In the natural habitats (western and eastern parts of North America, forest regions of Canada) $P$. pensylvanica is a pioneer species of felling sites, burnt areas and different disturbed territories [10,11]. 


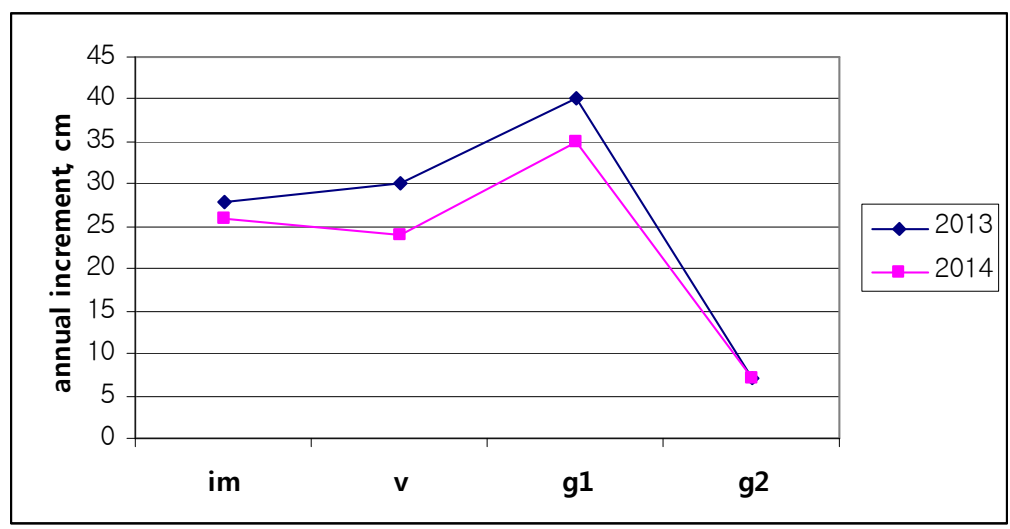

Fig. 2. Dynamics of annual increment in Prunus pensylvanica individuals at different age stages: $\mathrm{im}$ - immature, v - virginal, g1 - young generative, g2 -middle-aged generative.

The tree age in the wild does not exceed 40 years, fruiting begins at the age of 2 , the plants have a shallow root system and give abundant root shoots spreading over a considerable distance. Seeds are charaterized by poor germination (less than $10 \%$ ), but high seedling viability - up to $100 \%$, seed germination increases after fires and at succession disturbances $[12,13]$. In some regions of North America $P$. pensylvanica grows together with closely related $P$. virginiana and $P$. serotine which are characterized by high invasive activity on European continent.

In Novosibirsk $P$. pensylvanica exhibits dynamics of growth and development and reproducive ability typical of the species in natural habitats; it naturally regenerates both vegetatively and by seeds. For the first time self-seeding of $P$. pensylvanica was marked in the city in 1960[14]. In the urban environment the species is ecologically plastic, grows in various conditions, including areas with anthropogenic impact, regenerates more intensively on well illuminated sites. Daughter individuals of various ages occur at places of growing of $P$. pensylvanica maternal plants. The availability of uneven-aged generation of the introduced species testifies to the active process of its naturalization in local conditions [15]. Natural regeneration of $P$. pensylvanica was recorded in different Siberian cities $[16,17]$.

Such indicators as speed of growth, short pregenerative period, annual abundant fruitage, intensive vegetative regeneration and self-seeding, natural distribution on the territory at places of cultivation, ability to form self-reproducing populations allowed to state for the first time the beginning of naturalization of $P$. pensylvanica (status 3 ) in Novosibirsk. The data obtained testify to potential risk of the ingress of the alien species in urban forests and different natural communities. In this regard monitoring of the regeneration dynamics and prediction of $P$. pensylvanica spreading over the territory of Novosibirsk to prevent biological invasion of the species in the region is an important task.

\section{Conclusions}

The original data on natural vegetative regeneration and that by seed of the alien North American species $P$. pensylvanica introduced in Novosibirsk in the middle of the last century were obtained. It was revealed that the species actively regenerated naturally on urban objects and in dendrological collections spreading at a considerable distance from maternal individuals and going beyond places of cultivation. Fast growth, short pregenerative period, availability of abundant uneven-aged generation, high vegetative mobility, ability of colonization of new territories and formation of self-reproducing 
populations allowed to state for the first time the beginning of naturalization of $P$. pensylvanica in Novosibirsk.

\section{References}

1. D.M. Richardson, P. Pysek, PPG. 30, 409 (2006)

2. Y.K. Vinogradova, S.R. Mayorov, L.V. Khorun, The Black Book of the Flora of Central Russia (Moscow, 2010) in Russian

3. The Black Flora Book of Siberia (Novosibirsk, 2016) in Russian

4. L.N. Chindyaeva, A.P. Belanova, T.I. Kiseleva, RJBI. 2, 90 (2018)

5. V. Wagner, M. Chytrý, B. Jiménez-Alfaro, J. Pergl, S. Hennekens, I. Biurrun, I. Knollová, C. Berg, K. Vassilev, J.S. Rodwell, Ž. Škvorc, U. Jandt, J. Ewald, F. Jansen, I. Tsiripidis, Z. Botta-Dukát, L. Casella, F. Attorre, V. Rašomavičius, R. Ćušterevska, J.H.J. Schaminée, J. Brunet, J. Lenoir, J.-C. Svenning, Z. Kącki, M. PetrášováŠibíková, U. Šilc, I. García-Mijangos, J.A. Campos, F. Fernández-González, T. Wohlgemuth, V. Onyshchenko, P. Pyšek, Div. Distr. 23. 1 (2017)

6. A. Halarewicz, L. Zolnierz, For. Ecol. MaN. 313, 91 (2014)

7. J. M. Heberling, T. Kichey, G. Decocq, FEC. 6, 875 (2016)

8. T.A. Rabotnov, Experimental Phytocenology (MSU, Moscow, 1987) in Russian

9. A.A. Notov, Yu.K. Vinogradova, S.R. Mayorov, RJBI. 4, 54 (2010)

10. G.W.Wendel, Silvics Manual (published online, 2004 )

11. A.F. Rhoads, T.A. Block, Trees of Pennsylvania: a complete reference guide (Penn Press, Philadelphia, 2005)

12. P.L. Marks, PEMO. 44, 73 (1974)

13. L.R. Auchmoody, Can. J. For. Res. 9. 514-516 (1979)

14. A.V. Skvortsova, Z.G. Ekaterincheva, Recommendations on the use of introductions in forestry and gardening (Novosibirsk, 1981) in Russian

15. D.M. Richardson, P. Pysek, M. Rejmanek, M. Rejmanek, M.G. Barbour, F. D. Panetta C. J. West, Div. Distr. 6, 93 (2000)

16. Z.I. Luchnik, Decorative durability of shrubs (Kolos, Moscow, 1988) in Russian

17. A.I. Lobanov, M.I. Sedaeva, N.A. Konovalova, Fruit Grow, Seed Prod, Introd Wood plants. 20, 96 (2017) 